\title{
Factor VII Arg304GIn (FVII Padua) in North and South Americas: The Influence of Past "Forced" or Spontaneous Migrations
}

\author{
Antonio Girolami*, Silvia Ferrari, Elisabetta Cosi and Bruno Girolami \\ Department of Medicine, University of Padua Medical School, Padua, Italy
}

\begin{abstract}
Objective: To investigate the diffusion of the FVII Padua (Arg304GIn) defect in the Americas taking into consideration the "forced" or free emigration which occurred during the past.

Patients and methods: All homozygous cases of this FVII defect reported from the Mediterranean countries and from North and South America have been evaluated. Both papers with genetically proven cases and those without molecular biology studies were taken into consideration. The latter had to show low FVII level with rabbit brain thromboplastin and near normal levels with human placenta or human recombinant reagents.
\end{abstract}

Heterozygotes and Compound heterozygote were all considered. North America was pooled together with Central America.

Results: A total of 22 sure homozygotes were gathered ( 13 from the Mediterranean countries and 9 from the American ones) 3 proven and 7 highly probable homozygotes have been reported in North America, all in the USA. The ethnic origin of these patients was African-American.

On the contrary, there are 6 proven homozygotes in South America ( 3 in Argentina and 3 in Brazil). The ethnic background in Argentina is Caucasian and undetermined in Brazil. The number of sure heterozygotes in North America was 3 whereas the number in South America was 6 . In addition, three compound heterozygotes have been reported in the USA. One of the compound heterozygotes was African-American; in the other two the ethnic origin was unknown. Bleeding manifestation were mild or absent. Two patients had Deep Vein Thrombosis.

Conclusions: All patients with this defect described in the USA but one, were African-Americans whereas those described in Argentina were Caucasians. The ethnic background of the patients seen in Brazil could not be defined.

\section{Keywords}

Factor VII, North America, South America, Bleeding, Thrombosis

A FVII variant characterized by discrepant levels of FVII activity according to the thromboplastin used in the assay system was first described in Padua in 1978 [1]. Since that time the defect has been found in several parts of the world, mainly among the population of the Mediterranean countries and among the African-American population [2-5].

The main features of the defect are: very low activity levels when rabbit brain thromboplastins are used in the assay system and near normal or slightly reduced levels when thromboplastins of human origin (placenta) or human recombinant reagents are used. When ox-brain thromboplastin is used the FVII level is perfectly normal [1]. FVII antigen is also normal. The mutation responsible for the defect, an Arg304GIn substitution, was found in $1991[6,7]$. Because of the past migratory patterns existing between the Mediterranean countries and the Americas it was thought useful to investigate the effect these patterns had on the diffusion of a FVII special defect. It is likely that "forced" or spontaneous emigration patterns have influenced the presence of the mutation in North and South America.

*Corresponding author: Prof. Antonio Girolami, Department of Medicine, University of Padua Medical School, Via Ospedale 105, Padua, 35128, Italy, Tel: 003904-9821-3026, Fax: 003904965-7391

Accepted: August 24, 2019

Published online: August 26, 2019

Citation: Girolami A, Ferrari S, Cosi E, et al. (2019) Factor VII Arg304GIn (FVII Padua) in North and South Americas: The Influence of Past "Forced" or Spontaneous Migrations. Clin Hematol Res 2(1):16-19 
Citation: Girolami A, Ferrari S, Cosi E, et al. (2019) Factor VII Arg304GIn (FVII Padua) in North and South Americas: The Influence of Past "Forced" or Spontaneous Migrations. Clin Hematol Res 2(1):16-19

The purpose of the present study is to report about the different diffusion of the defect between North-Central America and South-America.

\section{Patients and Methods}

All sure homozygotes, namely demonstrated to be so by molecular biology studies (22 cases) and probably homozygotes who showed the peculiar clotting discrepancies (7 patients) were gathered from three main sources. Firstly, from two time-unlimited PubMed searches carried out on Jan 2010 and Jan 2018. Mesh items and side tables were used whenever available. Secondarily, personal files dealing with the patients seen in Padua and the large number of data accumulated on this defect during the past 50 years. Thirdly, from Reviews on FVII deficiency and case series reports of patients with congenital FVII deficiency. Single case reports were taken into consideration only if supported by molecular biology techniques. The search was limited to papers coming from the Mediterranean countries and the Americas. The total number of sure cases was 22 cases; that of probable cases were 7 . Age varied between 6 and 79 years; 12 were female and 10 , male.

For practical purposes Central America was pooled together with North America so that only two areas had to be dealt with, namely North-Central America and South America.

The population of the main countries involved (Argentina, Brazil and the USA) is reported in Table 1.

Original articles were obtained through the help of the Pinali Medical Library of our University.

Cross checking of the references listed at the end of each paper was carried out in order to avoid omissions. The investigation was carried out according to the Helsinki convention. All patients studied in Padua gave their consent.

Table 1: Approximate ethnic composition of Argentina Brazil and the USA as reported in Encyclopedia Britannica Year Book, 2017.

\begin{tabular}{|l|l|l|l|l|l|l|l|}
\hline Country & Total population & Caucasian & Africans & Mulattos & Mestizios & Others & Comments \\
\hline Argentina & 40 & $85 \%$ & $1 \%$ a) & $1 \%$ a) & $9 \%$ & $4 \%$ & a) Estimation \\
\hline Brazil & 204 & $47 \%$ & $8 \%$ & $42 \%$ b) & $?$ b) & $3 \%$ & b) Mestizos included with mulattos \\
\hline USA & 323 & $78 \%$ c) & $13 \%$ & $1 \%$ a) & $2 \%$ & $6 \%$ & c) Mexicans included (17\%) \\
\hline
\end{tabular}

Mulattos = Results of Caucasian-African mating; Mestizos = Result of a Caucasian-Indian mating; Others: Asian populations.

Table 2: Patients with proven or highly probable FVII Padua (Arg304GIn) reported in North-Central and South America.

\begin{tabular}{|c|c|c|c|c|c|c|}
\hline Authors (year) & $\begin{array}{l}\text { Proven } \\
\text { Homozygote } \\
\text { or Comp. Het. }\end{array}$ & $\begin{array}{l}\text { Proven } \\
\text { Heterozygote }\end{array}$ & $\begin{array}{l}\text { Probable } \\
\text { Homozygote }\end{array}$ & $\begin{array}{l}\text { Probable } \\
\text { Heterozygote }\end{array}$ & Countries & Comments \\
\hline Triplet, et al. [3] & n.r. & n.r. & 4 & n.r. & USA & $\begin{array}{l}\text { African-Americans one patient } \\
\text { had venous thrombosis }\end{array}$ \\
\hline Sabharwal, et al. [14] & 1 & n.r. & n.r. & n.r. & USA & $\begin{array}{l}\text { African-American; patient had } \\
\text { venous thrombosis }\end{array}$ \\
\hline Shurafa, et al. [15] & 1 & n.r. & n.r. & n.r. & USA & African-American \\
\hline Kuppuswamy, et al. [9] & 1 & n.r. & n.r. & n.r. & USA & $\begin{array}{l}\text { a) Ethnic background } \\
\text { unspecified; comp. het. with } \\
\text { GIn100Arg }\end{array}$ \\
\hline Krauss, et al. [14] & n.r. & n.r. & 2 & n.r. & USA & African-Americans \\
\hline Rodriguez, et al. [13] & None & 3 & n.r. & n.r. & Brazil & $\begin{array}{l}\text { Ethnic background } \\
\text { undetermined }\end{array}$ \\
\hline Barnett, et al. [17] & n.r. & n.r. & 1 & n.r. & USA & African-American \\
\hline Pollak, et al. [4] & 1 & 3 a) & n.r. & n.r. & USA & $\begin{array}{l}\text { African-Americans a) } 1 \text { patient } \\
\text { was compound het. With } \\
\text { Arg315Trp }\end{array}$ \\
\hline Herrmann, et al. [8] & None & 5 a) & n.r. & n.r. & $\begin{array}{l}\text { Costa Rica, } \\
\text { Venezuela, USA }\end{array}$ & $\begin{array}{l}\text { a) } 4 \text { Het. and } 1 \text { compound het. } \\
\text { With Gly365Cys (USA). Ethnic } \\
\text { group undetermined }\end{array}$ \\
\hline Kirkel, et al. [5] & 1 & None & n.r. & n.r. & USA & African-American \\
\hline Rabelo, et al. [10] & 3 & 1 & n.r. & n.r. & Brazil & Ethnic group undetermined \\
\hline Girolami, et al. [11] & 1 & 1 & n.r. & n.r. & Argentina & Caucasian \\
\hline Girolami, et al. [12] & 1 & 1 & n.r. & n.r. & Argentina & Caucasian \\
\hline
\end{tabular}

Het $=$ Heterozygote; Comp. Het. = Compound Heterozygote. 
Citation: Girolami A, Ferrari S, Cosi E, et al. (2019) Factor VII Arg304GIn (FVII Padua) in North and South Americas: The Influence of Past "Forced" or Spontaneous Migrations. Clin Hematol Res 2(1):16-19

\section{Results}

The number of proven or highly probable cases of FVII Padua in the Americas, is summarized in Table 2. There are at least 3 proven and 7 highly probable homozygotes in North-Central America. These patients have been studied in the USA and are all African Americans but one, whose ethnic background remained undetermined.

In addition there are three compound heterozygotes, one of whom associated with Arg315Trp [4] is also AfricanAmerican whereas the ethnic background of the other two has not been clarified $[8,9]$. The combined mutation in the latter two cases were: GIn100Arg and Gly365Cys [8,9].

A few heterozygotes have been reported in the USA among African-Americans and others in Costa Rica but without a definition, in this latter case, of their ethnic background $[4,8]$.

As far as South American is concerned, at least 6 proven homozygotes have been reported ( 3 in Brazil and 3 in Argentina) [10-12]. The ethnic background was Caucasian in the cases studied in Argentina [11,12] but was not reported for the cases seen in Brazil [10].

No compound heterozygotes has been reported so far in South America.

Finally, a few heterozygotes were described among Caucasians in Argentina $[11,12]$ and a few, without ethnic identification, in Venezuela and Brazil $[8,13]$.

As a whole it may be stated that the ethnic origin of the patients from Brazil, Costa Rica and Venezuela is undetermined $[9,11,13]$ whereas that of the patients from Argentina is Caucasian $[11,12]$ and that for the patients of the USA is African American [3-5,14-17].

Bleeding was mild or absent in all these patients. Interestingly, two of the homozygotes (one sure and one probable) showed venous thrombosis $[3,4]$.

\section{Discussion}

The Factor VII Arg304GIn mutation (FVII Padua) is one of the most thoroughly investigated. It is, a type II variant characterized by: 1) Discrepant levels of activity according to the thromboplastin used in the assay system 2) Little or no bleeding diathesis 3) A tendency towards venous thromboembolism 4) Normal levels of FVII antigen 5) FVIIa levels are also normal 6) Has no apparent effect on arterial thrombosis $[1,18]$.

FVII deficiency is a rare disease estimated to be present in 1: 500.000 people. However, FVII Padua is one of the most frequent forms, its clinical significance is important.

It has, in fact, been described in many parts of the world with a special concentration in the Mediterranean countries and in the USA [2].

Since all the homozygotes seen in the USA are AfricanAmericans, it became evident that other areas of the world besides Europe should be considered in order to explain the exclusive involvement of African-Americans in that country.

Recent large investigations of populations have shown a probable origin from "forced" emigration from West-Africa countries $[19,20]$.

The prevalence of the mutation shows some differences between the North-Central America and South-America. The USA and Brazil are the two countries that received the majority of "forced" immigrants.

Homozygotes appear more frequent in the USA as compared to Brazil even though one has to take into account the different size of the population of African origin (17\% in the USA, without taking into account the Mulattos, vs. $47 \%$ in Brazil including the Mulattos).

This could be the result of a discrepant presence of heterozygotes in the two populations of past "forced" immigrants or, more likely, of the different socio-economic conditions existing in the two countries. Different diagnostic capabilities in the two countries could also play a role.

Intraracial mating or marriages among the "forced" immigrants were almost the rule in the USA whereas it was not so in Brazil. This is well demonstrated by the observation that the population of mulattos in the USA census is not considered and it appears to be very low (about 1\%), whereas that seen in Brazil it has been estimated to be around $42 \%$. This could be, at least in part, due to a different classification of mulattos in the two countries. Mulattos in the USA are usually counted as African-Americans. However it could also be the result of the fact that interethnic or interracial matings or marriages in Brazil were much more frequent than in the USA [21,22].

The cases seen in Argentina are all Caucasians and this indicates their likely origin from Mediterranean countries (Italy, Spain in particular) [11,12]. An additional case was recently studied and this had also a Caucasian origin (unpublished observation).

On the contrary, all those seen in Brazil are probably of mixed origin, Caucasian in Southern Brazil (State of Santa Caterina, San Paolo and Rio Grande do Sul) and African-Brazilian in the States of Central and Northern Brazil $[10,13]$.

Unfortunately, no ethnic indication is reported in the papers from Brazil $[10,13]$ and therefore no sure conclusion can be drawn.

The discrepant background between Brazil and Argentina is due to the fact that no "forced" immigration from West Africa occurred in Argentina.

Even southern Brazil regions (Rio Grande do Sul, Santa Caterina, Sao Paulo), received less African "forced" immigrants [10]. In this regard, it may be underlined that in a small study of 401 Southern African-Brazilians no Arg304GIn mutation was found [13].

There are few informations about other American countries. Occasional heterozygotes have been reported in Costa Rica and Venezuela but no homozygote. Furthermore, no 
Citation: Girolami A, Ferrari S, Cosi E, et al. (2019) Factor VII Arg304GIn (FVII Padua) in North and South Americas: The Influence of Past "Forced" or Spontaneous Migrations. Clin Hematol Res 2(1):16-19

information about the ethnic origin of these patients is supplied [8]. No case has been reported from Mexico, country that received little "forced" immigration from Africa, if any.

In conclusion it may be stated that the Arg304GIn mutation at the homozygous state has been reported only in patients from Argentina, Brazil and the USA with discrepancies with regard to their ethnic group, Caucasian in Argentina, still undetermined in Brazil and African-Americans in the USA.

This study clearly demonstrates that the diffusion of genetic defects often follows known patterns of emigration, either "free" or "forced".

\section{Conflict of Interest}

The authors declare that they have no conflict of interest.

This study was supported in part by the "Associazione Emofilia ed altre coagulopatie delle Tre Venezie".

\section{References}

1. Girolami A, Fabris F, Dal Bo Zanon R, et al. (1978) Factor VII Padua: A congenital coagulation disorder due to an abnormal factor VII with a peculiar activation pattern. J Lab Clin Med 91: 387-395.

2. Girolami A, Berti de Marinis G, Bonamigo E, et al. (2011) Worldwide diffusion of FVII Arg304GIn coagulation defect (FVII Padua). Eur J Haematol 86: 135-139.

3. Triplett DA, Brandt JT, Batard MA, et al. (1985) Hereditary factor VII deficiency: Heterogeneity defined by combined functional and immunochemical analysis. Blood 66: 1284-1287.

4. Pollak ES, Russell TT, Ptashkin B, et al. (2006) Asymptomatic factor VII deficiency in African Americans. Am J Clin Pathol 126: 128-132.

5. Kirkel D, Lin TW, Fu SW, et al. (2010) Asymptomatic factor VII deficiency: Gene analysis and structure-function relationships. Blood Coagul Fibrinolysis 21: 91-94.

6. James HL, Kumar A, Girolami A, et al. (1991) Variant coagulation Factor $\mathrm{X}$ and VII with point mutations in a highly conserved motif in the substrate binding pocket, comparative molecular modelling. Thromb Haemost 69: 937.

7. O'Brien DP, Gale KM, Anderson JS, et al. (1991) Purification and characterization of factor VII 304-GIn: A variant molecule with reduced activity isolated from a clinically unaffected male. Blood 78: 132-140.

8. Herrmann FH, Wulff K, Auerswald G, et al. (2009) Factor
VII deficiency: Clinical manifestation of 717 subjects from Europe and Latin America with mutations in the factor 7 gene. Haemophilia 15: 267-280.

9. Kuppuswamy M, Sahbarwal A, Birktoff J, et al. (1993) Molecular characterization of human factor-VII Kansas (gk704)- substitution of Gln100 by Arg in one allele and of Arg304 by GIn possibly in the other allele. Thromb Haemost 69: 1291.

10. Rabelo FY, Jardim LL, Landau MB, et al. (2015) The molecular basis of low activity levels of coagulation factor VII: A Brazilian cohort. Haemophilia 21: 670-680.

11. Girolami A, Arias M, Sueldo E, et al. (2016) First report of homozygous factor VII Padua (Arg304GIn) defect in a family from Argentina. Hematol Med Onc 1: 1-5.

12. Girolami A, Sueldo E, Ferrari S, et al. (2018) Report of the second patient with a homozygous FVII Padua (Arg304GIn) defect in Northern Argentina. J Case 3: 036.

13. Rodrigues DN, Siqueira LH, Galizoni AM, et al. (2003) Prevalence of factor VII deficiency and molecular characterization of the F7 gene in Brazilian patients. Blood Coagul Fibrinolysis 14: 289-292.

14. Sabharwal AK, Kuppuswamy MN, Foster DC, et al. (1992) Factor VII deficiency (FVII Richmond, R304Q Mutant) associated with thrombosis. Circulation 86: 679.

15. Shurafa MS, Kumar A, Fair DS, et al. (1993) The molecular defect in factor VII Detroit is due to substitution of Arg (304) by Glu. FASEB J 7: 115.

16. Krauss JS, Matthews A, Oliver J, et al. (1994) African-American factor VII-deficient variants in Georgia (FVII variants). Am J Hematol 47: 239-241.

17. Barnett JM, Demel KC, Mega AE, et al. (2005) Lack of bleeding in patients with severe factor VII deficiency. Am J Hematol 78: 134-137.

18. Girolami A, Bertozzi I, de Marinis GB, et al. (2011) Activated FVII levels in factor VII Padua (Arg304GIn) coagulation disorder and in true factor VII deficiency: A study in homozygotes and heterozygotes. Hematology 16: 308-312.

19. http://www.internationalgenome.org/about

20. 1000 Genomes Project Consortium, Auton A, Brooks LD (2015) A global reference for human genetic variation. Nature 526: 68-87.

21. (1972) World Book Encyclopedia: Slavery; Vol. 17, Pag. 415; Vol. 14, Pag. 106. Field Educat Corp, Chicago.

22. (1963) Encyclopedia Britannica: Slavery; Vol. 20, Pag. 703-782. William Barstant Pub, Chicago.

DOI: $10.36959 / 831 / 378$

Copyright: (c) 2019 Girolami A, et al. This is an open-access article distributed under the terms of the Creative Commons Attribution License, which permits unrestricted use, distribution, and reproduction in any medium, provided the original author and source are credited. 